Research Article

\title{
Design and Implementation of the Array Logging Tool on Horizontal Production Logging
}

\author{
Wenguang Song $\mathbb{D}^{1},{ }^{1}$ Haiyu Chen $\mathbb{D}^{2}{ }^{2}$ Qiujuan Zhang, ${ }^{1}$ and Jiahao Zhang ${ }^{1}$ \\ ${ }^{1}$ School of Computer Science, Yangtze University, Jingzhou 434023, Hubei, China \\ ${ }^{2}$ Department of Computer, Zhaoqing Medical College, Zhaoqing 526020, Guangdong, China \\ Correspondence should be addressed to Haiyu Chen; jsj-3782036@126.com
}

Received 2 August 2020; Revised 18 October 2020; Accepted 28 October 2020; Published 1 December 2020

Academic Editor: Muhammad Mubashir Bhatti

Copyright (C) 2020 Wenguang Song et al. This is an open access article distributed under the Creative Commons Attribution License, which permits unrestricted use, distribution, and reproduction in any medium, provided the original work is properly cited.

\begin{abstract}
The measuring instruments have some errors in the measurement of high water cut production wells, and many domestic oil fields are also in high water cut state. The measured data from the conventional production logging instrument are all almost inaccurate. This project has designed a staggered probe array flow meter well logging apparatus based on the characteristic of electromagnetic wave specific retention meter that can fully cover the wellbore fluid and improve flow measurement accuracy. According to the application in horizontal wells, the accuracy of this measuring instrument now has been proved to be more than $90 \%$ and can meet the requirements of production logging interpretation in horizontal wells.
\end{abstract}

\section{Introduction}

Directional well drilling technology is becoming more and more perfect. Related completion technology is also constantly improved [1]. The number of horizontal wells is also increasing. Horizontal wells have gradually become one of the key technologies for high and stable production of various oil and gas fields. A large number of oil and gas fields have developed a certain scale of high angle wells and horizontal wells [2]. But, in production, many horizontal wells have low production and high water cut. The aquifer is located by production logging technology. This is very necessary. Several new horizontal well logging technologies have been developed by engineering and technical personnel through technical innovation [3]. For example, positioning and wet cable head pipe conveyed logging technology. Because the fluid in horizontal well is affected by gravity, the upper part is light phase and the lower part is heavy phase [4]. In the lower half, there is sediment and other phenomena, especially in the horizontal shaft of the horizontal well. This sediment can cause the measuring instrument not to operate normally [5].
Therefore, the array measurement instrument is used to reduce the interference of sediment on measurement data. This is a better method of measurement. According to this measurement method, the corresponding interpretation method and interpretation model are studied. This can improve the measurement accuracy of horizontal wells, and can lay the foundation for accurately finding aquifers [6].

Many oil fields at home and abroad are mining a large number of highly deviated wells and horizontal wells to improve the single well production capacity and improve the recovery of oil and gas [7]. But, in production logging, conventional measuring instruments cannot carry out the measurement work for high water cut and low yield horizontal wells. Foreign RAT [8], CAT [9], and other instruments are only suitable for high output of oil wells [10]. As for the low yield of oil well, the measurement accuracy needs to be further improved [11]. This project has found that using the 12 packer water holdup meter-combined electromagnetic wave measuring instruments can improve the measurement accuracy of a horizontal well through several experimental studies [12]. 


\section{The Designing of the Double Array Logging Tool}

Through the preliminary study, the temperature of fluid in the horizontal well is not more than 155 degrees Celsius, and the formation pressure is generally not more than $32 \mathrm{MPa}$ [13]. If the domestic production wells are in high water cut, the instrument can measure the water holding rate range between $0 \sim 100 \%$, and the precision should be above $98 \%$. Moreover, there may be a problem that is not easy to operate if the 12 holding water rate measuring instrument is in the same cross section of the array type measuring instrument [14] because of the limited working space in the production well [15]. So, here, the structure is designed as shown in Figures 1 and 2.

As shown in Figure 1, measuring probes are installed on the two cross section of the measuring instrument [16]. As shown in Figure 2, 6 water holding capacity measuring apparatus are distributed on each probe equably [17]. At the same time, the two cross sections of the probe are required to be uniformly distributed within the wellbore [18]. As shown in Figure 3, the effect of the distribution of 12 probes will be found in the longitudinal direction of the cross section [19].

As shown in Figure 3, probe 1, 3, 5, 7, 9, and 11 are 6 water holding capacity measuring apparatus at the same cross section, and probe $2,4,6,8,10$, and 12 are another 6 water holding capacity measuring apparatus at another same cross section [20]. As all these 12 probes are designed like this, the diameter of the instrument after contraction is reduced and contributes to the instrument carrying out survey work in wellbore [21].

Because the measuring instrument is limited by the diameter of the measuring shaft [22], the length of the probe is $120 \mathrm{~mm}$, the outer radius for the inner conductor is $2 \mathrm{~mm}$, the inner radius of the outer conductor is $7 \mathrm{~mm}$, and the outer radius of the outer conductor is $9 \mathrm{~mm}$ [23].

According to the transmission theory of electromagnetic field [24], the highest cutoff frequency or the minimum cutoff wavelength calculation formula of the transmission of the TEM wave (Transverse electric and magnetic field) inside a detector is

$$
\begin{gathered}
f_{T} \mathrm{EM} \max =\frac{300}{\pi(a+b) \varepsilon_{m}}, \\
\lambda_{T} \mathrm{EM} \min =\pi \sqrt{(a+b) \varepsilon_{m}} .
\end{gathered}
$$

The $f_{T}$ EM max in (1) is the highest cutoff frequency of the TEM mode with the same axis [25], and the $\lambda_{T}$ EM mim is the minimum cutoff wavelength of the TEM mode with the same axis [26]. $a$ is the outer radius for the inner conductor of the coaxial line [27]. $b$ is the inner radius of the outer conductor of the coaxial line. $\varepsilon_{m}$ is the dielectric constant of the medium in the same axis [28]. In the whole water, $a=2 \mathrm{~mm}$, $b=7 \mathrm{~mm}, \varepsilon_{m}=80 \mathrm{in}(1 \mathrm{in}=2.54 \mathrm{~cm})$, the highest cutoff frequency is $132.7 \mathrm{MHz}$, and the minimum cutoff wavelength calculation formula is $253 \mathrm{~mm}$, as mentioned above [29]. Therefore, the circuit structure of the probe of the 12 holding water rate measuring instruments [30] is as shown in Figure 4.

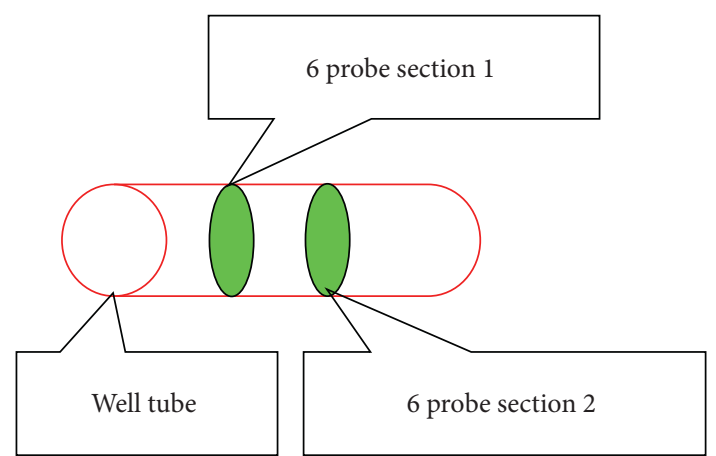

Figure 1: The instrument is measured in two cross sections in the wellbore.

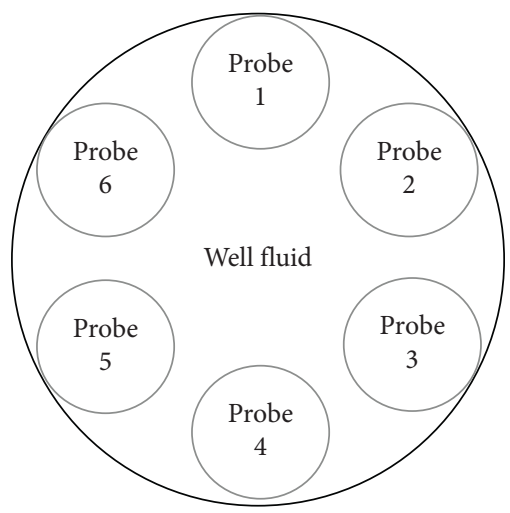

FIgURE 2: Six probes of the probe section distribution diagram.

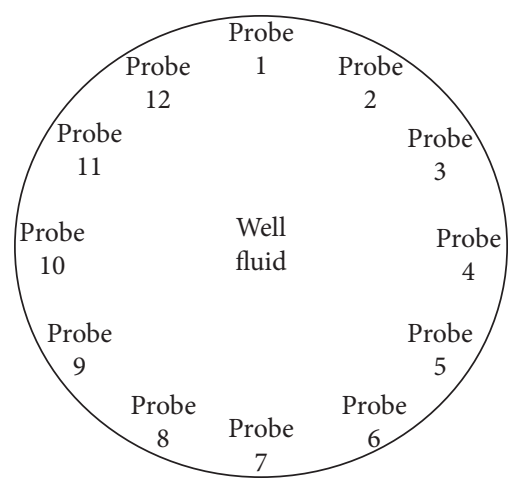

FIgURE 3: Twelve array probes are evenly distributed within the instrument.

\section{The Realization of the Measuring Instrument}

According to the previously described content, 12 probe array flow meter logging apparatus is designed as in Figure 5.

As shown in Figure 5, there two groups of the electromagnetic wave water holding rate meter measuring instrument; each group had 6 measuring probes, and 12 probes are covering the whole wellbore section equably. It is called the array logging tool.

There are 12 probes of the array logging tool in radial distribution of borehole to measure the accurate local stalemate rate. These cylindrical probes are 0.157 inches in 


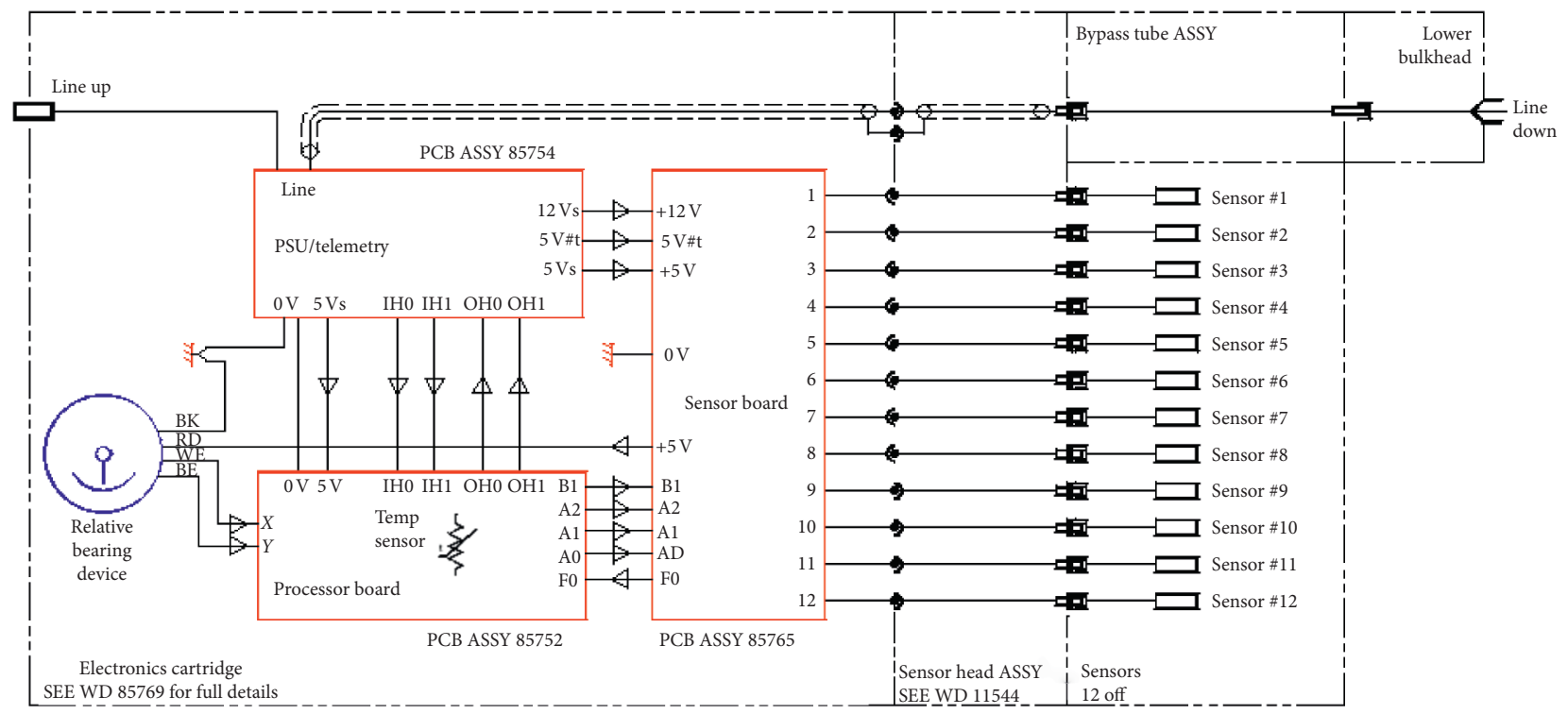

Figure 4: Twelve probes circuit logic structure.

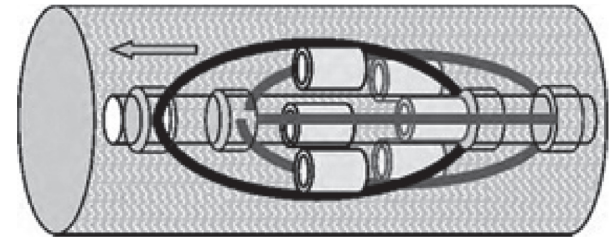

FIgURE 5: Twelve probes electromagnetic wave water holding rate meter measuring instrument.

diameter and 0.055 inches in length. It is set 0.35 inches away from the end of the movable support arm. Each probe resonates at different frequencies in oil [31], gas, and water. The tool judges the distribution of oil, gas, and water in the given area of the well by the difference of frequency resonance in the oil, gas, and water [32].

Corresponding to the capacitance value of the probe phase, the oscillation circuit produces a lower frequency in the water, a higher frequency in the oil, and the highest in the gas [33]. Probe frequency is typically sampled 72 times per minute. It can be repeated on the ground surface, which can process data and display the results [34]. The probe radius of each probe is about 0.01 inches. The probe can only reflect the capacitance value of the local environment around it. The calibration of the probe response can accurately measure the holdup of any two-phase mixture [35].

There are 6 probes are on the same cross section of the double array logging tool. The array logging tool is suitable for measuring the cross section holdup near the top and bottom of the wellbore perpendicular to the shaft [36]. The array of probe provides full coverage of the borehole. It can accurately determine the fluid in horizontal wells and highly deviated wells [37].

The probe calibration works are as follows. First, the borehole fluid is captured, and then, the probe is measured in the fluid, and the measured value is marked. For example, probe measures its value in the produced water and marks its measured value. The probe measures its value in the produced oil and marks its measured value. Probe calibration can take into account each probe specific fluid endpoint value and probe measurements in pure water or pure oil. For oil and water, these responses do not change much from the ground to the bottom. The next, the air point of each probe is recorded as the calibration value of the gas. Unlike the fluid, the air point varies with temperature and pressure. So, if possible, the gas needs to be calibrated on the spot.

Each probe has its own calibration value relative to oil, gas, and water [38]. Therefore, the probe can accurately measure the values of oil, gas, and water in wellbore [39]. For all probes, normalization is made so that each probe has the same measurement value for the same phase. Normalization allows minimal probe differences to be minimized, allowing 12 probe to achieve consistent response. All probes are normalized so that each phase has its own response value. Each probe also has a specific response value to the twophase mixture. The standardization process is controlled by borehole fluid and special logging tools used. Calibration must be performed before logging. This requires the use of collected borehole fluids. If there is no borehole fluid, it needs to be processed later to correct the logging data [40].

Once the double array logging tool is calibrated and the data are normalized, an image can be formed by processing the curves recorded by 12 probe. The oil, gas, and water have the corresponding color coding in the image. The singlephase water is blue. Single-phase oil is green. The singlephase gas is red. Bracket arm 1 can be positioned relative to the upper part of the borehole. So, when drawing a graph, we can use arm 1 to correct the position.

The double array logging tool can distinguish oil, gas, and water three phase. Therefore, according to the data measured by the array logging tool, the holdup of oil, gas, and water phases can be calculated.

This measuring apparatus has obtained good results in the process of horizontal well measurement construction 


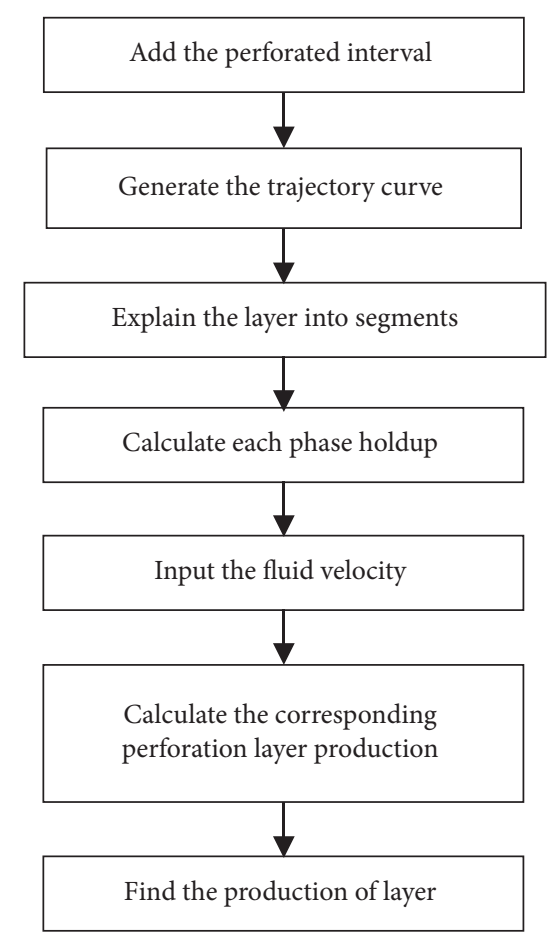

Figure 6: The chart of software design.
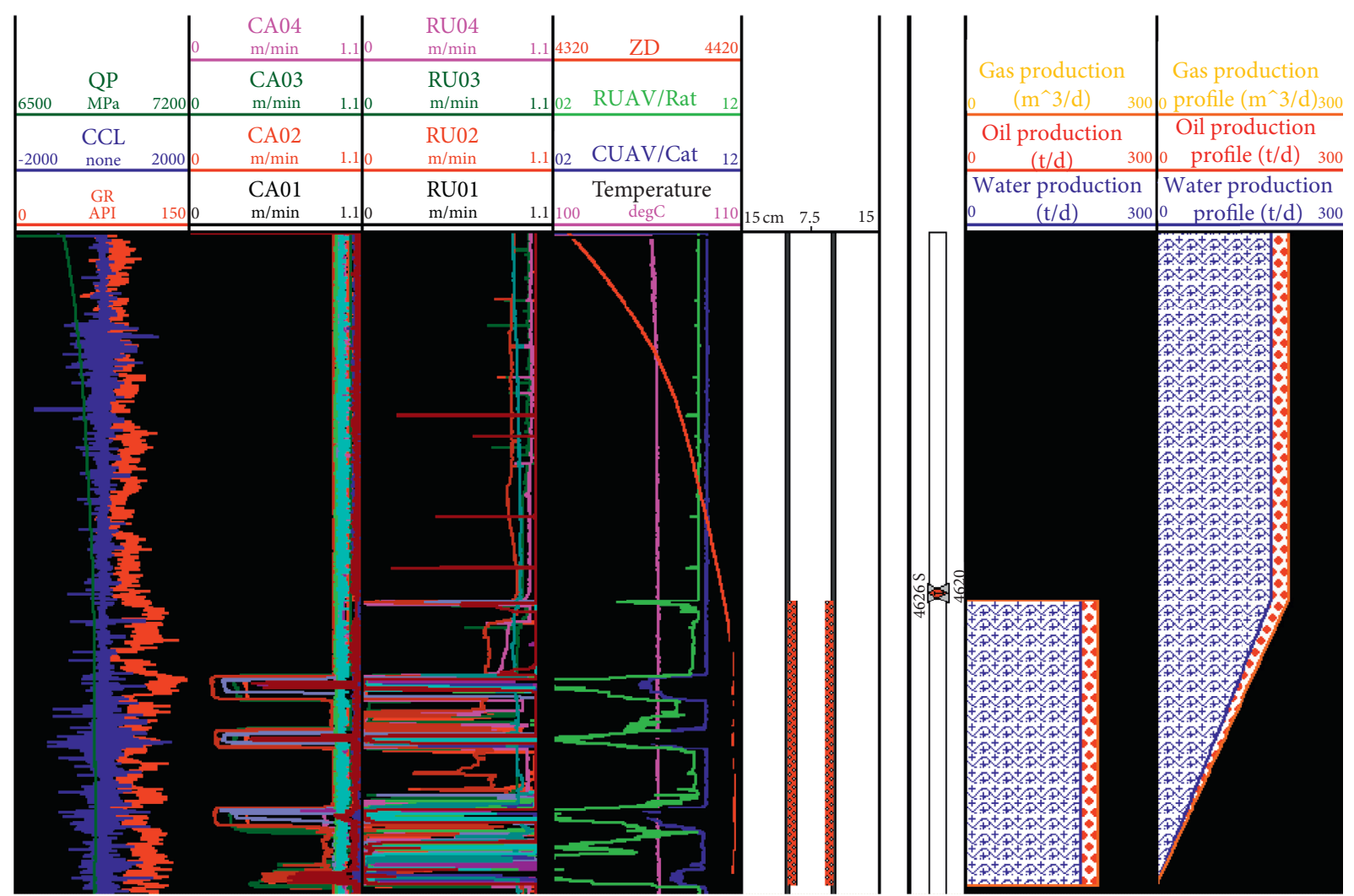

FIgURE 7: Simulation results calculated by the software.

conducted by a well area of Northwest China which is served by Shengli Oilfield Logging Company. We got the corresponding measurement data from using the flow meter well logging apparatus of the staggered probe array to carry out the production logging task and combined well logging interpretation software for production logging interpretation. Also, a set of horizontal well production interpretation software is developed. It is realized by using $\mathrm{VC}++6.0$ as the 
TABLE 1: The deviation of calculation and realistic of water holdup $Y_{w}$.

\begin{tabular}{lccc}
\hline Well serial number & Measured value (\%) & Actual value (\%) & Relative error (\%) \\
\hline 1 & 40.2 & 44 & 9.37 \\
2 & 31.7 & 34.5 & 9.01 \\
3 & 90.2 & 90.2 & 0.04 \\
4 & 60.7 & 64.6 & 6.49 \\
5 & 39.2 & 40.1 & 2.19 \\
6 & 62.8 & 66.1 & 5.26 \\
7 & 32.3 & 30.2 & 6.54 \\
\hline
\end{tabular}

TABLE 2: The deviation of calculation and realistic results.

\begin{tabular}{lcccc}
\hline & Calculation results (square per day) & Realistic results (square per day) & Variation (square per day) & Deviation (\%) \\
\hline Oil production & 27.031 & 25.5 & 1.531 & 6 \\
Liquid yield & 208.463 & 201.3 & 7.163 & 3.56 \\
\hline
\end{tabular}

development on the basis of FORWARD2.71. This software is designed as in Figure 6.

The emphasis is the calculation water holdup. That is described in the paper titled The Calculation Method of Production Log Holdup.

We developed a set of horizontal well production interpretation software. It is realized by using $\mathrm{VC}++6.0$ as the development on the basis of FORWARD2.7. The emphasis is the calculation water holdup. That is described in detail in the paper titled The Calculation Method of Production Log Holdup about CAT Instrument.

We can use the computer language to achieve the production log well software and use in the low production horizontal wells. We input the measured value of CAT, RAT, GR, CCL, QP, and ZD. The software can calculate the liquidproducing profile map. That is shown in Figure 7.

\section{The Application in Two-Phase Production Logging of Horizontal Wells}

We can use the computer language to achieve the production log well software and use in the low-production horizontal wells. We input the measured value of GR, CCL, QP, ZD, and 12 measurement of the electromagnetic wave holding capacity. The software can calculate the liquid-producing profile map. We use the double array logging tool to measure 7 horizontal wells and calculate the water holdup $Y_{w}$.

The data of 7 wells are shown in Table 1. Measured value is the value obtained from the double array logging tool measurements. Actual value is the actual water cut value of a well. Relative error is the error between measured value and actual value. Through data analysis, the maximum error is found to be $9.37 \%$. The minimum error is $0.04 \%$. The precision of the double array logging tool is more than $90 \%$. This kind of measuring instrument can meet the production requirement of horizontal well holdup measurement.

It can explain the wellhead metering data and interpretation of results data compared to the results, as shown in Table 2.

The production log interpretation is in accordance with the realistic results. It can measure the moisture content of the production log well. So, this method can accuracy calculate the results more than $90 \%$, and it can satisfy the requirements of production. The conclusion shows that this method has a certain practical value.

\section{Conclusions}

Because of the gravity factors, the differentiation of fluid in the horizontal wellbore occurs that the light phase is in the upper part and the lower part is in the lower part. The traditional production logging instrument cannot truly reflect the fluid shape in horizontal wells. So, it must analyze the flow pattern of multiphase flow in horizontal wells. It researches the importance of the multiphase flow mechanism in horizontal wells to interpretation of production profile data.

The double array logging tool can be designed according to the flow pattern of multiphase flow in horizontal wells. It can well measure the fluid holdup values in the horizontal wellbore. The paper developed the horizontal section interpretation module for single-phase and twophase flow (oil-water two-phase; gas water two-phase) horizontal well production, according to the research model, in the Visual $\mathrm{C}++$ compiling environment. Also, this paper applied the double array logging tool in one Western China horizontal well. We use the module to interpretation of actual logging data. The interpretation results are basically consistent with the actual production situation of the wellhead. It is proved that the developed double array logging tool and the interpretation model of the interpretation method are feasible. It can solve the problem of quantitative interpretation of production profile logging data in horizontal wells.

The paper developed the interpretation module of the array capacitance instrument and array resistance instrument in horizontal well. It can further improve the accuracy of qualitative interpretation by the double array logging tool, which accumulated experience for further quantitative interpretation of array data. There are two novelty points in this study.

First, the design of simulation experiment on the large diameter used in the actual production logging instrument is continuous and packer. This paper analyzed numerical 
simulation, the flow, fluid flow characteristics, and the response of the holdup measurement instrument.

Second, it designed the double array logging tool. Also, this paper compiled the interpretation module of the horizontal well production section. This module is used to interpret the actual logging data of horizontal wells, and the interpretation results are basically consistent with the actual production situation at the wellhead, which indicates that that the proposed interpretation model is feasible.

The system has problems and suggestions. First, it will improve the production logging technique in the horizontal well and make full use of the existing domestic conventional production profile measuring instrument. Second, it can measure multiprobe, multi-instrument integral, and local combination on the same target parameters and verify the accuracy of the instrument response. Third, we can also absorb the advanced technology of foreign countries, use the physical theory of electricity (such as a microrotor flow meter) and optics (such as GHOST), and constantly develop new or improved measurement sensor for two-phase flow of a horizontal well.

\section{The Future Work}

The array logging tools will be introduced furthermore, and the response rules will be clarified. Then, the cooperative interpretation of various logging information will be carried out. Further research on multiphase flow simulation will put forward the appropriate instrument combination and interpretation model.

\section{Data Availability}

The data used to support the findings of this study can be obtained from the corresponding author upon request.

\section{Conflicts of Interest}

The authors declare that they have no conflicts of interest.

\section{Acknowledgments}

This work was supported by Xinjiang Uygur Autonomous Region Innovation Environment (talent, base) Construction Foundation (Xinjiang NSFC Program Foundation 2020D01A132): Research and implementation of the horizontal well inversion optimization interpretation method, Jingzhou Science Technology Foundation (2019EC61-06), Hubei Science and Technology Demonstration Foundation (2019ZYYD016), 2019 Zhaoqing Science and Technology Innovation Guidance Project (201904030401), and Vertical Research Planning Project of Cloud Computing and Big Data Professional Committee of Higher Vocational College of Guangdong Institute of Higher Education in 2019 (GDJSKT19-18).

\section{References}

[1] G. Frisch, T. Perkins, and Q. John, "Integra-ting wellbore flow images with a conventional production log interpretation method," in Proceedings of the SPE Annual Technical Conference and Exhibition, San Antonio, TX, USA, September 2002.

[2] W. Song, H. Guo, and X. Shi, "Levenberg-marquardt algorithm used in reservoir damage production of logging prediction," in Proceedings of the 2011 2nd International Conference on Information Technology and Scientific Management, pp. 62-65, Nanjing, China, September 2011.

[3] W. Song, H. Guo, and J. Wang, "The BP algorithm used in reservoir damage predictionof speed-sensitive by improved," in Proceedings of the 2011 2nd International Conference on Information Technology and Scientific Management, pp. 5861, Nanjing, China, September 2011.

[4] X.-D. Wang, G.-D. Yu, and Z.-P. Li, "Productivity of horizontal wells with complex branches," Petroleum Exploration and Development, vol. 6, pp. 729-733, 2006.

[5] J. Wang and R. Jiang, "Physical modeling of a sidetrack horizontal well production to improve oil recovery," Science in China (Series E: Technological Sciences), vol. 44, no. 4, pp. 353-364, 2002.

[6] H. Zhao and X. Lu, "China's crude oil production from 2005 to 2010 (10,000 tons)," China Oil \& Gas, vol. 25, no. 2, pp. 22-25, 2011.

[7] Q. Zhao and T. Wenguang, "Achievements of China's coalbed methane exploration and development," China Oil \& Gas, vol. 2, pp. 27-31, 2008.

[8] L. Liming, Q. Jishun, S. Yang et al., "Analysis and evaluation on horizontal well seepage models and their developing trends," Oil \& Gas Geology, vol. 34, no. 6, pp. 821-827, 2013.

[9] B. Ji, "Progress and prospects of enhanced oil recovery technologies at home and abroad," Oil \& Gas Geology, vol. 33, no. 1, pp. 111-117, 2012.

[10] Y. Han, "Application of horizontal well technology to liaohe oilfield," China Oil \& Gas, vol. 1, pp. 35-37, 2008.

[11] J. Xu, N. Dong, C. Zhu et al., "Application of seismic data to the design of horizontal well trajectory in tight sandstone reservoirs," Oil \& Gas Geology, vol. 33, no. 6, pp. 909-913, 2012.

[12] L.-S. Zhai, N. D. Jin, X. K. Zheng et al., "The analysis and modeling of measuring data acquired by using combination production logging tool in horizontal simulation well," Chinese Journal of Geophysics, vol. 55, no. 4, pp. 1411-1421, 2012.

[13] Q. Tang, "Application of gesturing technology in the development of Sulige gas field-case studies of the Su10 and Su53 blocks," Oil \& Gas Geology, vol. 34, no. 3, pp. 388-393, 2013.

[14] Y. Zong, Measurement of the Properties of Oil-Water TwoPhase Flow in Inclined and Horizontal Pipes, Tianjin University, Tianjin, China, 2009.

[15] D. Piron, B. Hubert, D. Heddadj, G. Pérès, H. Vincent, and D. Cluzeau, "Indicators of earth wormbioturbation to improve visual assessment of soil structure," SoilÆTillage Research, vol. 173, pp. 53-63, 2017.

[16] H. Xu, W. Huang, Q. Hou et al., "The effects of probiotics administration on the milk production, milk components and fecal bacteria microbiota of dairy cows," Science Bulletin, vol. 62, no. 11, pp. 767-774, 2017.

[17] Y. Sun, M. Liang, X. Jin, P. Ji, and J. Shan, "Experimental and modeling study of the regular polygon angle-spiral liner in ball mills," Chinese Journal of Mechanical Engineering, vol. 30, no. 2, pp. 363-372, 2017.

[18] Y. Li, B. Li, C. Tian, Y. Zhu, B. Song, and Q. Qian, "A method of production profile quick prediction based on typical curves: a case study of the upper shale large multi-layered sandstone 
reservoir, Rumaila Oilfield, Iraq," Petroleum Exploration and Development Online, vol. 43, no. 6, pp. 189-201, 2016.

[19] A. Patel, N. Arora, J. Mehtani, V. Pruthi, and A. P. Pruthi, "Assessment of fuel properties on the basis of fatty acid profiles of oleaginous yeast for potential biodiesel production," Renewable and Sustainable Energy Reviews, vol. 77, pp. 604-616, 2017.

[20] M. O. Igono, G. Bjotvedt, and H. T. Sanford-Crane, "Environmental profile and critical temperature effects on milk production of Holstein cows in desert climate," International Journal of Biometeorology, vol. 36, no. 2, pp. 38-45, 1992.

[21] R. Mikuła, W. Nowak, J. Jaśkowski, P. Maćkowiak, and E. Oszmałek, "Effects of different starch sources on metabolic profile, production and fertility parameters in dairy cows," Polish Journal of Veterinary Sciences, vol. 14, no. 1, pp. 79-86, 2011.

[22] V. T. Dosseva-Panova, C. L. Popova, and V. E. Panov, "Subgingival microbial profile and production of proinflammatory cytokines in chronic periodontitis," Folia Medica, vol. 56, no. 3, pp. 152-160, 2014.

[23] C. Barton and M. Cai, "Equatorial wave expansion of instantaneous flows for diagnosis of equatorial waves from data: formulation and illustration," Advances in Atmospheric Sciences, vol. 34, no. 10, pp. 1219-1234, 2017.

[24] C. Liu, X. L. Wang, D. Deng et al., "Optimal spacing of sequential and simultaneous fracturing in horizontal well," Journal of Natural Gas Science and Engineering, vol. 29, pp. 85-96, 2016.

[25] M. Wei, Y. Duan, M. Dong, and Q. Fang, "Blasingame decline type curves with material balance pseudo-time modified of a multi-fractured horizontal well in a shale gas reservoir," Journal of Natural Gas Science and Engineering, vol. 31, pp. 340-350, 2016.

[26] B. Li, Y.-P. Liang, X.-S. Li, and L. Zhou, "A pilot-scale study of gas production from hydrate deposits with two-spot horizontal well system," Applied Energy, vol. 176, pp. 48-57, 2016.

[27] L. Cao, X. Li, C. Luo, L. Yuan, J. Zhang, and X. Tan, "Horizontal well transient rate decline analysis in low permeability gas reservoirs employing an orthogonal transformation method," Journal of Natural Gas Science and Engineering, vol. 33, pp. 59-67, 2016.

[28] J. Hou, B. Wei, Q. Du, J. Wang, Q. Wang, and G. Zhang, "Production prediction of cyclic multi-thermal fluid stimulation in a horizontal well," Journal of Petroleum Science and Engineering, vol. 146, pp. 949-958, 2016.

[29] Z. Wang, D. Gao, and J. Liu, "Multi-objective sidetracking horizontal well trajectory optimization in cluster wells based on DS algorithm," Journal of Petroleum Science and Engineering, vol. 147, pp. 771-778, 2016.

[30] Y. S. Wei, A. L. Jia, D. B. He, and J. L. Wang, "A new method in predicting productivity of multi-stage fractured horizontal well in tight gas reservoirs," Journal of Natural Gas Geoscience, vol. 1, pp. 397-406, 2016.

[31] W. Cheng, H. Gao, Y. Jin, M. Chen, and G. Jiang, "A study to assess the stress interaction of propped hydraulic fracture on the geometry of sequential fractures in a horizontal well," Journal of Natural Gas Science and Engineering, vol. 37, pp. 69-84, 2016.

[32] G. Cui, S. Ren, L. Zhang et al., "Geothermal exploitation from hot dry rocks via recycling heat transmission fluid in a horizontal well," Energy, vol. 128, pp. 156-162, 2017.

[33] X.-P. Li, L.-N. Cao, C. Luo, B. Zhang, J.-Q. Zhang, and X.-H. Tan, "Characteristics of transient production rate performance of horizontal well in fractured tight gas reservoirs with stress-sensitivity effect," Journal of Petroleum Science and Engineering, vol. 158, pp. 92-106, 2017.

[34] L. Xu, W. Xu, C. Zhang, X. Liu, and J. Hu, "Multiple parameters' estimation in horizontal well logging using a conductance-probe array," Flow Measurement and Instrumentation, vol. 40, pp. 152-160, 2014.

[35] L. Wan, X. Kong, and F. Xia, "Joint range-Doppler-angle estimation for intelligent tracking of moving aerial targets," IEEE Internet of Things Journal, vol. 5, no. 3, pp. 1625-1636, 2018.

[36] L. Wan, L. Sun, X. Kong, Y. Yuan, K. Sun, and F. Xia, “Taskdriven resource assignment in mobile edge computing exploiting evolutionary computation," IEEE Wireless Communications, vol. 26, no. 6, pp. 94-101, 2019.

[37] F. Wen, Z. Zhang, K. Wang, G. Sheng, and G. Zhang, "Angle estimation and mutual coupling self-calibration for ULAbased bistatic MIMO radar," Signal Processing, vol. 144, pp. 61-67, 2018.

[38] F. Wen and J. Shi, "Fast direction finding for bistatic EMVSMIMO radar without pairing," Signal Process, vol. 173, Article ID 107532, 2020.

[39] D. Meng, X. Wang, M. Huang, L. Wan, and B. Zhang, "Robust weighted subspace fitting for DOA estimation via block sparse recovery," IEEE Communications Letters, vol. 24, no. 3, pp. 563-567, 2020.

[40] X. Wang, L. Wang, X. Li, and G. Bi, "Nuclear norm minimization framework for DOA estimation in MIMO radar," Signal Processing, vol. 135, pp. 147-152, 2017. 